\title{
Field study and regression modeling on soil water distribution with mulching and surface or subsurface drip irrigation systems
}

\author{
Mohamed A. Mattar ${ }^{1,3^{*}}$, Ahmed A. Al-Othman ${ }^{1}$, Hosam O. Elansary ${ }^{2}$, \\ Ahmed M. Elfeky ${ }^{1}$, Akram K. Alshami ${ }^{1}$ \\ (1. Agricultural Engineering Department, College of Food and Agriculture Sciences, King Saud University, Riyadh 11451, Saudi Arabia; \\ 2. Plant Production Department, College of Food and Agriculture Sciences, King Saud University, Riyadh 11451, Saudi Arabia; \\ 3. Agricultural Engineering Research Institute (AEnRI), Agricultural Research Centre, Giza, Egypt)
}

\begin{abstract}
The soil water status was investigated under soil surface mulching techniques and two drip line depths from the soil surface $\left(D_{L}\right)$. These techniques were black plastic film (BPF), palm tree waste (PTW), and no mulching (NM) as the control treatment. The $D_{L}$ were $15 \mathrm{~cm}$ and $25 \mathrm{~cm}$, with surface drip irrigation used as the control. The results indicated that both the BPF and PTW mulching enhanced the soil water retention capacity and there was about $6 \%$ water saving in subsurface drip irrigation, compared with NM. Furthermore, the water savings at a $D_{L}$ of $25 \mathrm{~cm}$ were lower $(15-20 \mathrm{~mm})$ than those at a $D_{L}$ of $15 \mathrm{~cm}(19-24 \mathrm{~mm})$, whereas surface drip irrigation consumed more water. The distribution of soil water content $\left(\theta_{v}\right)$ for BPF and PTW were more useful than for NM. Hence, mulching the soil with PTW is recommended due to the lower costs and using a $D_{L}$ of $15 \mathrm{~cm}$. The $\theta_{v}$ values were derived using multiple linear regression (MLR) and multiple nonlinear regression (MNLR) models. Multiple regression analysis revealed the superiority of the MLR over the MNLR model, which in the training and testing processes had coefficients of correlation of 0.86 and 0.88 , root mean square errors of 0.37 and 0.35 , and indices of agreement of 0.99 and 0.93 , respectively, over the MNLR model. Moreover, $D_{L}$ and spacing from the drip line had a significant effect on the estimation of $\theta_{v}$.
\end{abstract}

Keywords: palm tree waste mulching, plastic film mulching, soil water distribution, regression models DOI: $10.25165 /$ j.ijabe.20211402.5200

Citation: Mattar M A, Al-Othman A A, Elansary H O, Elfeky A M, Alshami A K. Field study and regression modeling on soil water distribution with mulching and surface or subsurface drip irrigation systems. Int J Agric \& Biol Eng, 2021; 14(2): $142-150$.

\section{Introduction}

In arid regions, such as Saudi Arabia, the absence of an effective water management system results in high water loss during irrigation ${ }^{[1]}$. The climate is also hyper arid, with these factors having a big effect on the limited water supplies and agriculture $^{[2]}$. Therefore, drip irrigation has been adopted, as it is assumed to be the foremost efficient and valuable source for stabilizing the utilization of water in comparison with other systems. Surface drip irrigation (DI) often decreases water loss due to less water evaporation and deep percolation ${ }^{[1]}$. Despite these advantages, there are also several disadvantages of applying DI, including the possibility of damage, direct exposure of the drip lines to the sun, and the occurrence of salinity. Thus, subsurface drip irrigation (SDI) has been proposed as a more useful method

Received date: 2019-06-13 Accepted date: 2020-10-14

Biographies: Ahmed A. Al-Othman, Associate Professor, research interests: irrigation systems engineering and water management, Email: othmana@ ksu.edu.sa; Hosam O. Elansary, Associate Professor, research interests: irrigation water management, Email: helansary@ksu.edu.sa; Ahmed M. Elfeky, Researcher Assistant, research interests: irrigation systems engineering and water management, Email: 441106440@student.ksu.edu.sa; Akram K. Alshami, Researcher Assistant, research interests: irrigation systems engineering and water management, Email: 441106718@student.ksu.edu.sa.

*Corresponding author: Mohamed A. Mattar, Associate Professor, research interests: irrigation systems engineering and water management. Agricultural Engineering Department, College of Food and Agriculture Sciences, King Saud University, Riyadh 11451, Saudi Arabia. Tel.: +966-11-4676024, Email: mmattar@ksu.edu.sa. because it uses less water than DI because of reduced evaporation from the soil surface ${ }^{[3,4]}$. SDI is often used to control the quantity of water applied without having any significant environmental damage as a result of flow elimination and deep penetration ${ }^{[5]}$. Overall, this method reinforces the production of crops by decreasing water waste ${ }^{[6-8]}$. SDI is more effective than DI because it provides water directly to the root zone ${ }^{[9]}$. However, this system's performance can be affected depending on the space between the emitters and the lined depth of the drip lines ${ }^{[7]}$.

Some precautionary measures should be taken in the SDI system for crop production. According to Enciso et al. ${ }^{[7]}$, there should be suitable spacing between emitters, taking into account the depth and type of drip lines during the design process to enhance irrigation efficiency and increase productivity ${ }^{[10]}$. Magwenzi $^{[11]}$ stated that the depth of the drip lines can vary from 10 to $20 \mathrm{~cm}$. Several studies have been conducted on SDI in different crops. Najafi ${ }^{[12]}$ studied the effect of drip line depths of 15 and $30 \mathrm{~cm}$ on tomato crop yield. He found that the best yield was obtained at a drip line depth of $15 \mathrm{~cm}$. In contrast, Zhuge et al. ${ }^{[13]}$ found that a drip line depth of $30 \mathrm{~cm}$ provided better root distribution and nutrient absorption in tomato cultivation than at depths of 20 and $40 \mathrm{~cm}$. Patel and Rajput ${ }^{[14]}$ found that a drip line depth of $10 \mathrm{~cm}$ was best with $60.7 \mathrm{~cm}$ of irrigation water applied when planting onions in sandy, loamy soil. Al-Harbi et al. ${ }^{[15]}$ also found that using a drip line of $35 \mathrm{~cm}$ improved growth and reduced evaporation from the soil surface. A study by Douh and Boujelben ${ }^{[16]}$ showed that the soil water content was recorded up to a depth of $80 \mathrm{~cm}$ from the surface in drip lines of $15 \mathrm{~cm}$ used to 
produce eggplant and the water saving was $23.2 \%$ higher than that of the DI system. Moreover, the soil profile of the water distribution was more constant in the SDI system than the DI system. Çolak et al. ${ }^{[17]}$ revealed that evaporation losses were lower in SDI receiving slightly less water than the DI in eggplant. In addition, Al-Ghobari and Dewidar ${ }^{[18]}$ reported that the soil water contents in SDI were higher than those in DI during the tomato growth stages. Further, Pisciotta et al. ${ }^{[19]}$ used drip lines at a depth of $35 \mathrm{~cm}$ to prevent damage from tillage during the cultivation of grapevines.

In the field of agriculture, several techniques other than SDI, such as soil surface mulching, have been explored to improve water absorption $^{[20]}$. These techniques are commonly used to avoid evaporation loss from the soil surface and enhance crop growth environments to increase crop yields ${ }^{[6,21-25]}$. One soil surface mulching technique that has been used in recent years is crop straw, which minimizes soil water evaporation, ameliorates the soil's physical and chemical properties, and promotes biological activity ${ }^{[26-29]}$. In maize cultivation, Li et al. ${ }^{[23,24]}$ found that straw mulching saved about $35 \%$ of water during the growth stages. Plastic film mulching is a well-evolved technique that is currently being used for cultivation, especially in areas where irrigation water is scarce ${ }^{[30]}$. It has been shown to enhance thermal conditions and increase water storage in the upper soil layers ${ }^{[31,32]}$, improving crop growth and water productivity ${ }^{[33,34]}$. In some cases, an SDI system mulched with plastic film is used to increase vegetable production $^{[35]}$, for example, Zotarelli et al. ${ }^{[36]}$ and Baghani et al. ${ }^{[37]}$. Wang et al. ${ }^{[38]}$ and Ma et al. ${ }^{[39]}$ reported that using plastic film mulching increased the yield of maize and potato in semiarid regions by maintaining soil moisture in the upper layers.

A combination of SDI and mulching can possibly reduce soil water evaporation in an arid environment. Therefore, this study aimed to (1) explore the status of the volumetric soil water content $\left(\theta_{v}\right)$ under different drip line depths and soil surface mulching using black plastic film (BPF) and palm tree waste (PTW), (2) develop empirical models using multiple regression analyses to estimate the $\theta_{v}$ values for soil profiles under an SDI for different mulching to study important parameters affecting $\theta_{v}$.

\section{Materials and methods}

\subsection{Field conditions and experimental design}

The experiment was conducted at the Agricultural Research Farm in Dirab, Riyadh $\left(24.4195^{\circ} \mathrm{N}, 46.65^{\circ} \mathrm{E}\right.$, and $552 \mathrm{~m}$ a.s.l.) during the summer months of 2018. Climatic data were recorded as monthly averages during the experimental period (June, July, August, and September) as follows: $36.6^{\circ} \mathrm{C}, 37.4^{\circ} \mathrm{C}, 35.8^{\circ} \mathrm{C}$, and $34.6^{\circ} \mathrm{C}$, respectively, for air temperatures; $10.1 \%, 11.8 \%, 13.7 \%$, and $13.5 \%$, respectively, for relative humidity; $5.6 \mathrm{~m} / \mathrm{s}, 6.1 \mathrm{~m} / \mathrm{s}$, $6.6 \mathrm{~m} / \mathrm{s}$, and $5.6 \mathrm{~m} / \mathrm{s}$, respectively, for maximum wind speed; and $24.7 \mathrm{MJ} / \mathrm{m}^{2} \cdot \mathrm{d}, 24.8 \mathrm{MJ} / \mathrm{m}^{2} \cdot \mathrm{d}, 23.4 \mathrm{MJ} / \mathrm{m}^{2} \cdot \mathrm{d}$, and $23.2 \mathrm{MJ} / \mathrm{m}^{2} \cdot \mathrm{d}$, respectively, for solar radiation. Moreover, there was no rainfall during these months.

The field experiments were planned and implemented, as shown in Figure 1. The DI system was designed using a water tank, pump, pressure gauges, pressure regulators, flow meter, ball, relief, solenoid valves, main lines, sub-mains, and drip lines. A $5000 \mathrm{~L}$ water tank was used in the irrigation network. The drip lines (16 mm inner diameter and $1 \mathrm{~mm}$ thickness) were placed at the soil surface (i.e., DI) and two depths from the soil surface $\left(D_{L}\right)$ of $15 \mathrm{~cm}$ and $25 \mathrm{~cm}$. The emitters had a discharge rate of $4 \mathrm{~L} / \mathrm{h}$ at $150 \mathrm{kPa}$ operating pressure with a spacing of $30 \mathrm{~cm}$ on the drip line. Two soil surface mulches, BPF and PTW, were applied, as well as

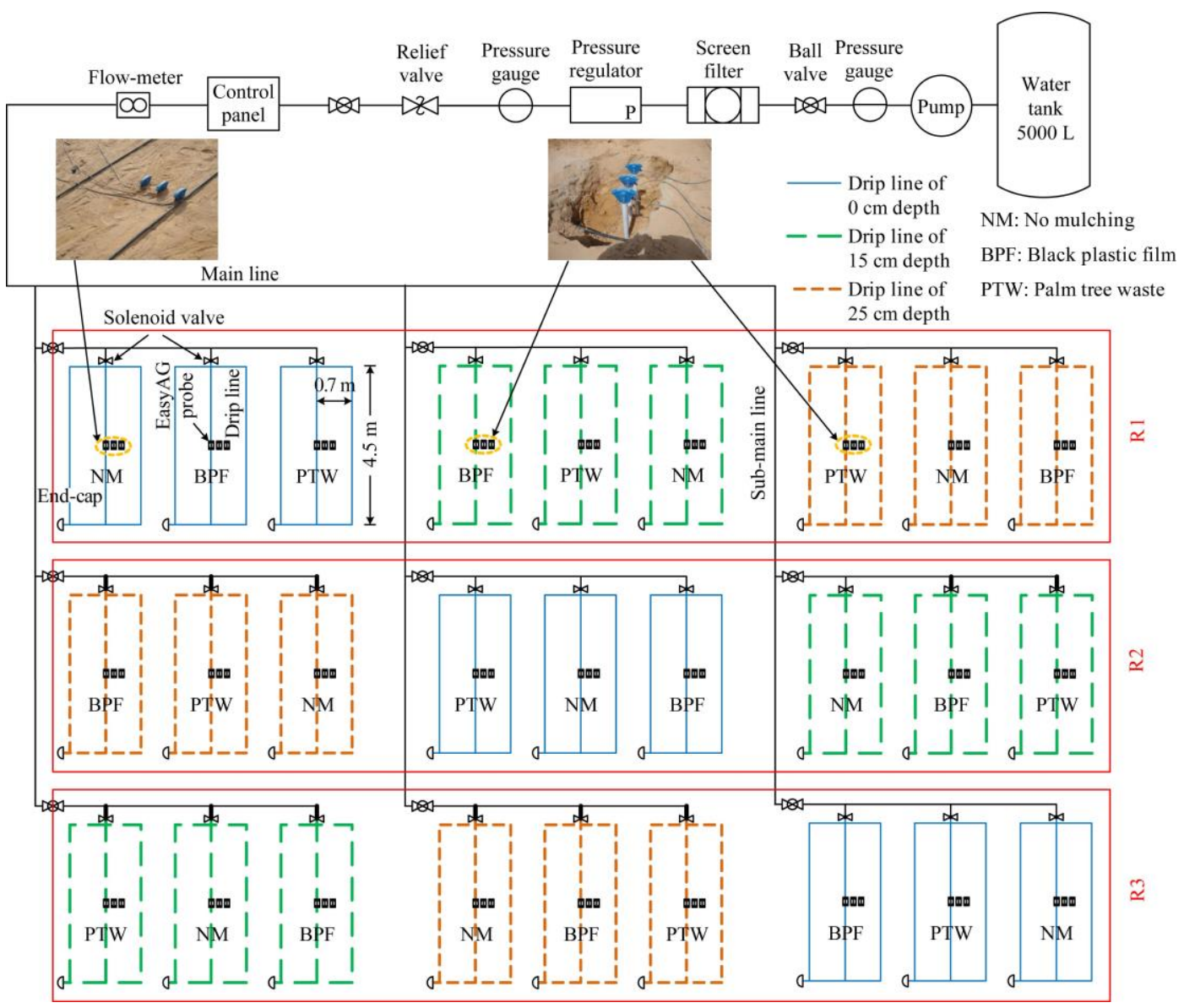

Figure 1 Experimental layout 
no mulching (NM). A randomized complete block design was used with three replications (Figure 1). Before conducting the experiments, three soil samples were collected from different depths to determine physical and chemical properties (see Table 1).
Three samples of irrigation water were also analyzed to determine their chemical properties, which were an electrical conductivity value of $4.5 \mathrm{dS} / \mathrm{cm}, \mathrm{pH} 7.48$, and total dissolved solids of $2880 \mathrm{mg} / \mathrm{kg}$.

Table 1 Physical and chemical properties of soil samples from the experimental site

\begin{tabular}{|c|c|c|c|c|c|c|c|c|c|c|c|c|c|c|}
\hline \multirow{2}{*}{$\begin{array}{l}\text { Soil depth } \\
\text { /cm }\end{array}$} & \multicolumn{3}{|c|}{ Particle size distribution $/ \%$} & \multirow{2}{*}{ Soil texture } & \multicolumn{4}{|c|}{ Physical properties } & \multicolumn{6}{|c|}{ Chemical properties } \\
\hline & Clay & Silt & Sand & & $\theta_{i} / \%$ & $\mathrm{FCl} \%$ & $W P / \%$ & $\rho_{b} / \mathrm{g} \cdot \mathrm{cm}^{-3}$ & $E C / \mathrm{dS} \cdot \mathrm{m}^{-1}$ & $\mathrm{pH}$ & $\mathrm{CaCO}_{3}$ & $\mathrm{Na}$ & $\mathrm{K}$ & $\mathrm{P}$ \\
\hline \multicolumn{15}{|l|}{ Plot 1} \\
\hline $0-25$ & 3.2 & 22.5 & 74.3 & Loamy sand & 1.22 & 14.58 & 3.04 & 1.51 & 1.47 & 7.85 & 25.54 & 61 & 116 & 31.1 \\
\hline $25-50$ & 3.2 & 22.5 & 74.3 & Loamy sand & 1.36 & 15.99 & 3.39 & 1.41 & 2.4 & 7.73 & 27.04 & 181 & 115 & 21.8 \\
\hline \multicolumn{15}{|l|}{ Plot 2} \\
\hline $25-50$ & 1.95 & 16.25 & 81.8 & Loamy sand & 1.15 & 15.15 & 2.45 & 1.40 & 2.37 & 7.87 & 24.75 & 139 & 110 & 9.3 \\
\hline \multicolumn{15}{|l|}{ Plot 3} \\
\hline $0-25$ & 4.45 & 16.25 & 79.3 & Loamy sand & 1.37 & 17.57 & 3.05 & 1.50 & 3.09 & 7.81 & 24.75 & 330 & 81 & 24.9 \\
\hline $25-50$ & 0.7 & 12.5 & 86.8 & Sand & 0.93 & 14.81 & 2.06 & 1.40 & 2.05 & 7.91 & 23.34 & 218 & 70 & 34.2 \\
\hline
\end{tabular}

Note: Plot 1: drip line depth $=0 \mathrm{~cm}$; Plot 2: drip line depth $=15 \mathrm{~cm}$; Plot 3: drip line depth $=25 \mathrm{~cm} ; \theta_{i}$ : Initial water content; $F C$ : field capacity; $W P$ : Wilting point; $\rho_{b}$ : Soil bulk density; $E C$ : Electrical conductivity.

\subsection{Irrigation water}

An irrigation schedule was applied using soil sensors to continuously monitor the $\theta_{v}$ and supply a suitable amount of irrigation water to the planned irrigation treatment. Its purpose was to maximize the irrigation efficiency by applying the appropriate amount of water needed to replenish the soil water to the desired level at field capacity $(F C)$. However, no crops were planted in this study. Therefore, the depth of water applied to reach the $F C\left(D_{w}\right)$ was calculated for a soil depth $(D)$ of $50 \mathrm{~cm}$ at increments of $10 \mathrm{~cm}$ using Equation (1):

$$
D_{w}=\sum_{i=1}^{n} D_{i}\left(F C_{i}-\theta_{v i}\right)
$$

where, $D_{w}$ is the depth of water applied to reach the field capacity, $\mathrm{mm} ; n$ is the number of sensors; $D_{i}$ is the soil depth at the $i^{\text {th }}$ sensor, $\mathrm{mm} ; F C_{i}$ is the field capacity of the soil at the $i^{\text {th }}$ sensor; and $\theta_{v i}$ is the soil water content at the $i^{\text {th }}$ sensor.

\subsection{Monitoring soil water content}

Three EasyAG probes (Sentek Sensor Technologies, Stepney, Australia), including several sensors (electrical capacitance) were used and installed in each plot to monitor the values of $\theta_{v}$ at a soil depth from 10 to $50 \mathrm{~cm}$. These probes were placed as follows: the first was placed directly at the emitter, the second was placed at a $15 \mathrm{~cm}$ spacing from the drip line $(S)$, and the third was at $S$ of $30 \mathrm{~cm}$, as shown in Figure 1.

The electrical capacitance from the probe recorded a scaled frequency reading $(S F)$ in the field to provide a $\theta_{v}$ using a calibration equation, as follow:

$$
\begin{gathered}
S F=\frac{\left(F_{A}-F_{S}\right)}{\left(F_{A}-F_{W)}\right.} \\
\theta_{v}=\left(\frac{S F-C}{A}\right)^{\frac{1}{B}}
\end{gathered}
$$

where, $F_{A}, F_{S}$, and $F_{W}$ are frequency readings in the air, soil, and water, respectively, and $A, B$, and $C$ are constants obtained from calibration procedure of the probes (Table 2).

Table 2 Constants of Equation (3) for three sensors after calibration

\begin{tabular}{lcccc}
\hline \multicolumn{1}{c}{ Sensor location } & $A$ & $B$ & $C$ & $R^{2}$ \\
\hline Directly on drip line & 60.619 & 0.109 & -71.356 & 0.942 \\
At spacing of $15 \mathrm{~cm}$ from drip line & 476.132 & 0.014 & -485.695 & 0.844 \\
At spacing of $30 \mathrm{~cm}$ from drip line & 507.365 & 0.011 & -513.789 & 0.751 \\
\hline
\end{tabular}

\subsection{Multiple regression analysis}

The multiple linear regression (MLR) and multiple nonlinear regression (MNLR) models were derived using the data acquired from the field experiment. The dependent variable is estimated when the values of the independent variables are obtained from the linear and nonlinear combinations in a multiple regression model. Based on the results of the MLR and MNLR, the effects of the influencing factors on $\theta_{v}$ can be better explained. The corresponding model expressions can be described as follows:

MLR model:

$$
\hat{Y}=a_{0}+a_{1} X_{1}+a_{2} X_{2}+a_{3} X_{3}+\ldots+a_{m} X_{m}
$$

where, $\hat{Y}$ is the predicted value of the dependent variable, $a_{i}(i=$ $0, \ldots, m)$ are the estimated regression coefficients for the linear relation, and $X_{i}(i=1, \ldots, m)$ are the independent variables.

MNLR model:

$$
\hat{Y}=b_{0} \times X_{1}^{b_{1}} \times X_{2}^{b_{2}} \times X_{3}^{b_{3}} \times \ldots \times X_{m}^{b_{m}}
$$

where, $b_{i}(i=0, \ldots, m)$ are the estimated regression coefficients for the nonlinear relation.

The regression models were developed, and the mulching types (MT) that were categorized as 0 for NM, 2 for BPF, and 3 for PTW, $D_{L}, S$, and $D$ were considered as independent variables, whereas $\theta_{v}$ was the dependent variable. In the present study, 135 data points were used to derive all regression models. The models were developed using $60 \%$ of the data for the training process, and $20 \%$ of the data were used to test the models. The remaining data were used for model validation. During the validation process, the performance of the developed regression models were checked under NM, BPF, and PTW. The statistical characteristics of $\theta_{v}$ data for each process are provided in Table 3. The SPSS Statistics software package (version 16.0; SPSS; Chicago, IL, USA) was used to perform the regression analysis.

Statistical performance evaluation criteria were calculated to test the goodness of fit of the regression models during the training, testing, and validation processes. The criteria utilized were the coefficients of correlation $(r)$, root mean square errors (RMSE), and index of agreement $(I A) . \quad r$ measured the degree of correlation between the measured and calculated $\theta_{v}$ values with values close to 1.0 indicating a perfect agreement, and it was calculated as follows:

$$
r=\frac{\sum_{i=1}^{N}\left(M_{i}-\bar{M}\right)\left(C_{i}-\bar{C}\right)}{\sqrt{\sum_{i=1}^{N}\left(M_{i}-\bar{M}\right)^{2} \sum_{i=1}^{N}\left(C_{i}-\bar{C}\right)^{2}}}
$$


where, $M_{i}$ is the measured value; $C_{i}$ is the calculated value; $N$ is the number of data; $\bar{M}$ is the average measured value; and $\bar{C}$ is the average calculated value; RMSE expresses the error in the same units as the variable ${ }^{[40]}$ and measures the difference between the calculated and measured values ${ }^{[41]}$ by:

$$
R M S E=\sqrt{\frac{\sum_{i=1}^{N}\left(M_{i}-C_{i}\right)^{2}}{N}}
$$

IA represents the ratio between the mean square error and the potential error, as defined by Willmot ${ }^{[42]}$ :

$$
I A=1-\frac{\sum_{i=1}^{N}\left(M_{i}-C_{i}\right)^{2}}{\sum_{i=1}^{N}\left(\left|C_{i}-\bar{M}\right|+\left|M_{i}-\bar{M}\right|\right)^{2}}
$$

IA has a range from 0 to 1 , with a perfect fit at $1^{[40]}$.

Table 3 Statistical parameters of $\theta_{v}$ data used for the training, testing, and validation processes

\begin{tabular}{lcccccc}
\hline & $X_{m}$ & $X_{a}$ & $X_{n}$ & $S_{x}$ & $K_{x}$ & $C_{s x}$ \\
\hline Training process & 15.60 & 14.17 & 12.28 & 0.723 & -0.291 & -0.010 \\
Testing process & 15.36 & 13.98 & 12.45 & 0.708 & -0.123 & -0.030 \\
Validation process & & & & & & \\
NM & 14.81 & 13.75 & 12.58 & 0.784 & -0.799 & -0.410 \\
BPF & 15.32 & 14.05 & 13.10 & 0.820 & -1.134 & 0.585 \\
PTW & 15.29 & 14.13 & 12.97 & 0.771 & -1.132 & -0.028 \\
\hline Note: $X_{n}:$ maxin
\end{tabular}

Note: $X_{m}$ : maximum value; $X_{a}$ : mean value; $X_{n}$ : minimum value; $S_{x}$ : standard deviation; $K_{x}$ : kurtosis coefficient; $C_{s x}$; skewness coefficient; NM: no mulching; BPF: black plastic film; PTW: palm tree waste.

\subsection{Statistical analysis}

An analysis of variance was performed using CoStat version 6.303 (CoStat Version 6.303 Copyright 1998-2004) to determine the effects of $D_{L}$ and MT on the measured $\theta_{v}$. The treatment means were separated using a least significant difference test at $p=0.05$.

\section{Results and discussion}

\subsection{Applied water}

The BPF treatment achieved water savings of $10.55 \%, 6.79 \%$, and $7.02 \%$ at $D_{L}$ of $0 \mathrm{~cm}, 15 \mathrm{~cm}$, and $25 \mathrm{~cm}$, respectively, compared with the NM treatment, which had $93.5 \mathrm{~mm}, 69 \mathrm{~mm}$, and $73 \mathrm{~mm}$ of applied water, respectively, while the PTW treatment achieved water savings of $5.96 \%, 4.94 \%$, and $5.26 \%$, respectively (Figure 2). The water applied under DI, at a $D_{L}$ of $0 \mathrm{~cm}$, with any type of mulching was conserved less than that applied under SDI, at a $D_{L}$ of 15 or $25 \mathrm{~cm}$, where soil surface evaporation rates were high $^{[4,43]}$. Additionally, as shown in Figure 2, using BPF or PTW above a $D_{L}$ of $25 \mathrm{~cm}$ required the application of more water than a
$D_{L}$ of $15 \mathrm{~cm}$. Therefore, the use of SDI with BPF or PTW mulching retained soil moisture and decreased the amount of water required $^{[44]}$. Thus, it is preferable to use PTW mulching at a $D_{L}$ of $15 \mathrm{~cm}$, as there are fewer additional costs.

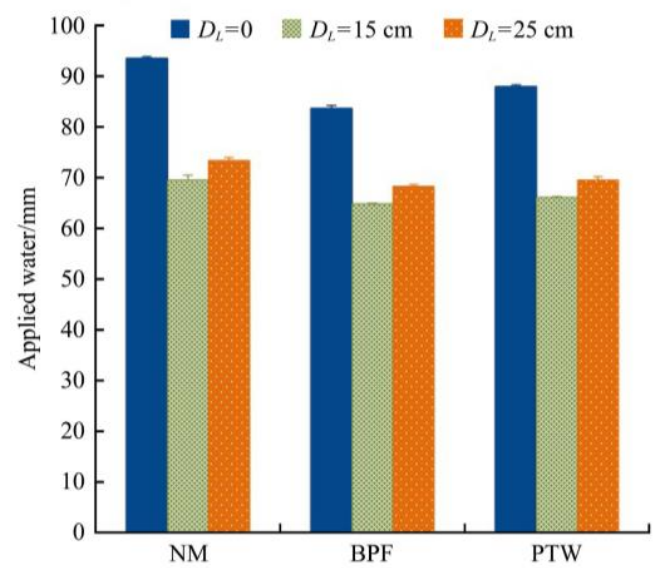

Note: NM: no mulching; BPF: black plastic film; PTW: palm tree waste.

Figure 2 Water applied under different mulching types at different drip line depths from the soil surface $\left(D_{L}\right)$

\subsection{Effect of mulching type on soil water content}

Regardless of the $D_{L}$ treatments, Tables 5 shows that there were significant effects of MT on $\theta_{v}$ values at different $S$. The average $\theta_{v}$ values for the BPF treatment were the highest, followed by the PTW treatment in both drip systems (Figure 3). For the $D_{L}$ of $0 \mathrm{~cm}$ with BPF mulching at $S$ of 0,15 , and $30 \mathrm{~cm}$, the $\theta_{v}$ values increased by $4.08 \%, 1.33 \%$, and $1.76 \%$, respectively, compared with the NM treatment, while there were increases of $2.39 \%$, $0.89 \%$, and $0.84 \%$, respectively, with PTW mulching (Figure 3). For a $D_{L}$ of $15 \mathrm{~cm}$, the BPF and PTW treatments at an $\mathrm{S}$ of $0 \mathrm{~cm}$ had $\theta_{v}$ values that were $3.65 \%$ and $1.38 \%$ higher, respectively, than those of the NM treatment, while there were increases of $1.02 \%$ and $0.58 \%$, respectively, at an $S$ of $15 \mathrm{~cm}$ and increases of $1.58 \%$ and $0.75 \%$, respectively, at an $S$ of $30 \mathrm{~cm}$ (Figure 3). For a $D_{L}$ of $25 \mathrm{~cm}$, there were increases of $2.74 \%$ and $1.13 \%$, respectively, in the $\theta_{v}$ values at an $S$ of $0 \mathrm{~cm}$ for the BPF and PTW treatments compared with the NM treatment. Additionally, the corresponding values of the BPF and PTW treatment increased by $3.97 \%$ and $2.91 \%$, respectively, at an $S$ of $15 \mathrm{~cm}$ and by $3.15 \%$ and $2.20 \%$, respectively, at an $S$ of $30 \mathrm{~cm}$ (Figure 3). The use of BPF or PTW mulching substantially limits the flux of water vapor from the soil surface into the air ${ }^{[23,24,45,46]}$. Although the purchase cost of BPF is high, it can be replaced by PTW, which is available at no additional cost

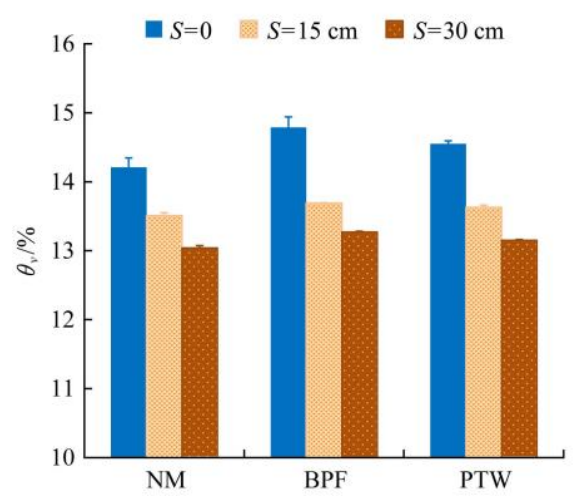

a. $D_{L}=0 \mathrm{~cm}$

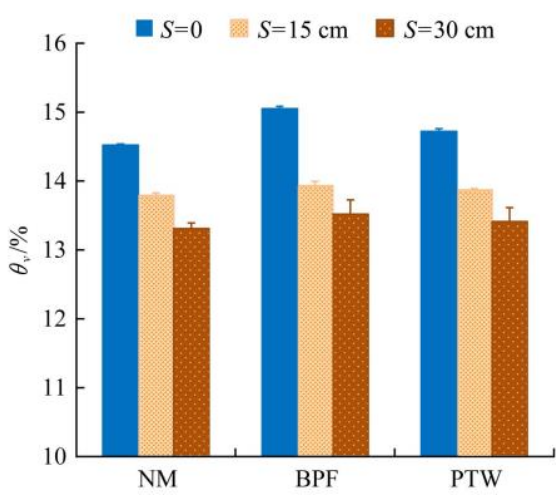

b. $D_{L}=15 \mathrm{~cm}$

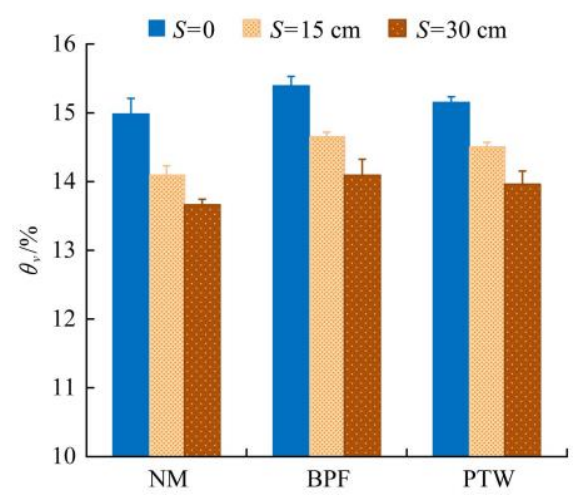

c. $D_{L}=25 \mathrm{~cm}$

Note: NM: no mulching; BPF: black plastic film; PTW: palm tree waste

Figure 3 Average soil water content $\left(\theta_{v}\right)$ under different spacing from drip line $(S)$ and mulching types at different drip line depths from the soil surface $\left(D_{L}\right)$ 


\subsection{Effect of the depth of the drip line on soil water content}

Regardless of the mulching treatments, the $D_{L}$ significantly affected $(p<0.01)$ the average $\theta_{v}$ values at different $S$ (Table 4$)$, with a $D_{L}$ of $25 \mathrm{~cm}$ having the highest $\theta_{v}$ values, in contrast to a $D_{L}$ of $0 \mathrm{~cm}$. The average $\theta_{v}$ values for a $D_{L}$ of $25 \mathrm{~cm}$ were highest at $S$ of 0,15 , and $30 \mathrm{~cm}$ under the NM treatment, which increased by $3.17 \%$, $2.18 \%$, and $2.63 \%$ at a $D_{L}$ of $15 \mathrm{~cm}$, respectively, and increased by $5.42 \%, 4.29 \%$, and $4.75 \%$, respectively, at a $D_{L}$ of $0 \mathrm{~cm}$ (Figure 3 ). These findings are consistent with findings by Mokh et al. ${ }^{[47]}$, who observed that $\theta_{v}$ values increased with increasing $D_{L}$. The $\theta_{v}$ values in the BPF and PTW treatments under different $D_{L}$ showed a similar trend (Figure 3). For the BPF treatment, a $D_{L}$ of $25 \mathrm{~cm}$ produced the highest $\theta_{v}$ values, which were $2.26 \%$ (at an $S$ of $0 \mathrm{~cm}$ ), $5.17 \%$ (at an $S$ of $15 \mathrm{~cm}$ ), and $4.22 \%$ (at an $S$ of $30 \mathrm{~cm}$ ) higher than the $\theta_{v}$ values at a $D_{L}$ of $15 \mathrm{~cm}$ and $4.06 \%, 7.01 \%$, and $6.18 \%$ higher, respectively, than the $\theta_{v}$ values at a $D_{L}$ of $0 \mathrm{~cm}$. For the PTW treatment, the $\theta_{v}$ values at a $D_{L}$ of $25 \mathrm{~cm}$ were $2.92 \%, 4.54 \%$, and $4.10 \%$ higher than those at a $D_{L}$ of $15 \mathrm{~cm}$ at $S$ of 0,15 , and $30 \mathrm{~cm}$, respectively, while there were increases of $4.12 \%, 6.38 \%$, and $6.16 \%$, respectively, comparison with a $D_{L}$ of $0 \mathrm{~cm}$. A small difference in average $\theta_{v}$ values was observed between the $D_{L}$ of $15 \mathrm{~cm}$ and $D_{L}$ of $25 \mathrm{~cm}$. Therefore, a $D_{L}$ of $15 \mathrm{~cm}$ should be selected because of the lower drilling costs. Installing a drip line below the soil surface and not exposing it to the sun increases the $\theta_{v}$ value, as moisture is not lost ${ }^{[48]}$.

Table 4 Results of variance analysis of $\theta_{v}$ values under mulching type (MT) and drip line depth from the soil surface $\left(D_{L}\right)$ at different spacing from the drip line $(S)$

\begin{tabular}{lccc}
\hline \multicolumn{1}{c}{ Treatments } & $S=0 \mathrm{~cm}$ & $S=15 \mathrm{~cm}$ & $S=30 \mathrm{~cm}$ \\
\hline MT & $* *$ & $* *$ & $*$ \\
No mulching & $14.57^{\mathrm{c}}$ & $13.79^{\mathrm{b}}$ & $13.33^{\mathrm{b}}$ \\
Black plastic film & $15.08^{\mathrm{a}}$ & $14.09^{\mathrm{a}}$ & $13.63^{\mathrm{a}}$ \\
Palm tree waste & $14.81^{\mathrm{b}}$ & $13.99^{\mathrm{a}}$ & $13.51^{\mathrm{ab}}$ \\
$\mathrm{LSD}_{0.05}$ & $0.17^{\mathrm{a}}$ & $0.11^{\mathrm{a}}$ & 0.19 \\
$D_{L}$ & $* *$ & $* *$ & $* *$ \\
Surface drip & $14.52^{\mathrm{c}}$ & $13.61^{\mathrm{c}}$ & $13.15^{\mathrm{c}}$ \\
Subsurface drip at $15 \mathrm{~cm}$ depth & $14.76^{\mathrm{b}}$ & $13.86^{\mathrm{b}}$ & $13.41^{\mathrm{b}}$ \\
Subsurface drip at $25 \mathrm{~cm}$ depth & $15.14^{\mathrm{a}}$ & $14.42^{\mathrm{a}}$ & $13.91^{\mathrm{a}}$ \\
LSD $_{0.05}$ & 0.17 & $0.11^{\mathrm{a}}$ & 0.20 \\
${\text { MT } \times D_{L}}^{\mathrm{n}}$ & $\mathrm{ns}$ & $*$ & $\mathrm{~ns}$ \\
\hline
\end{tabular}

Note: ns: Non-significant; *: Significant at $p<0.05$; **: Significant at $p<0.01$. Mean values in columns followed with different letters are significantly different based on the least significant difference test at $p<0.05\left(\operatorname{LSD}_{0.05}\right)$.

\subsection{Soil water distribution}

Figures 4-6 illustrate the effects of MT and $D_{L}$ on the $\theta_{v}$ distribution throughout the soil profile. $D_{L}$ of 15 and $25 \mathrm{~cm}$ had the best uniformity of $\theta_{v}$ distribution contour lines at different $\mathrm{S}$. When $\mathrm{S}$ increased, the $\theta_{v}$ bulb's spread decreased, in agreement with Assouline ${ }^{[49]}$, Grabow et al. ${ }^{[50]}$, Badr ${ }^{[51]}$, Shirahatti et al. ${ }^{[52]}$, and Nasrabad et al. ${ }^{[53]}$. Since the horizontal movement of water is limited in sandy soils, there should be close spacing between the emitters $^{[54]}$. In addition, the vertical movement was higher than the horizontal movement under the SDI system ${ }^{[43,55,56]}$.

There were significant effects of interactions between the MT and $D_{L}$ on the $\theta_{v}$ values at an $\mathrm{S}$ of $15 \mathrm{~cm}$ (Table 4). For $D_{L}$ of 0,15 , and $25 \mathrm{~cm}$ at a $D$ of $0-20 \mathrm{~cm}$, the $\theta_{v}$ values of BPF were increased by $0.96 \%, 3.05 \%$ and $5.56 \%$, respectively, compared with NM, while the $\theta_{v}$ values of PTW were $1.25 \%, 2.91 \%$, and $5.41 \%$, higher respectively, in agreement with Wang et al. ${ }^{[57]}$ and Liu et al. ${ }^{[58]}$. Ma et al. ${ }^{[39]}$ found that using plastic films significantly increased the $\theta_{v}$ by $12.9 \%$ at a $D$ of $0-20 \mathrm{~cm}$, compared with the traditional method. The use of either BPF or PTW mulching maintains water evaporation and encourages the movement of water into the topsoil layers, which enhances $\theta_{v}$ during the initial growth stage of crops ${ }^{[44]}$ The surface soil layer has a lower $\theta_{v}$ (i.e., not completely wet) for SDI than DI, thereby reducing the soil evaporation in $\mathrm{SDI}^{[48]}$. At the active root depth $(0-40 \mathrm{~cm})$ for most crops, the NM at an $S$ of $15 \mathrm{~cm}$ had average $\theta_{v}$ values of $13.87 \%$ and $14.13 \%$ for $D_{L}$ of 15 and $25 \mathrm{~cm}$, respectively (Figure 4). In sandy soils, SDI enhances the water recovery capacity ${ }^{[59]}$, while in loamy soils, a $D_{L}>10 \mathrm{~cm}$ is recommended to prevent wetting of the soil surface during irrigation $^{[60]}$. The average $\theta_{v}$ corresponding values for BPF and PTW were $14.02 \%$ and $13.97 \%$, respectively, at a $D_{L}$ of $15 \mathrm{~cm}$, and $14.63 \%$ and $14.54 \%$, respectively, at a $D_{L}$ of $25 \mathrm{~cm}$ (Figures 5 and 6). This increased $\theta_{v}$ of BPF and PTW treatments could be attributed to minimal soil water loss, which has an important role in crop management and growth ${ }^{[61,62]}$. Ashrafuzzaman et al. ${ }^{[63]}$ reported that water in the form of fog fell into the topsoil layer due to the vapors formed by water trapped inside the mulch. Figures 4-6 show that when the $D_{L}$ increased, a saturation bulb of $\theta_{v}$ distribution below emitters became more controllable moving downward, especially with BPF and PTW, which also changed the shape of the bulb from a circular shape to an ellipse. This is in agreement with Thorbum et al. ${ }^{[64]}$, who showed that SDI controls the amount of water and the spread of $\theta_{v}$ toward the soil surface. $\mathrm{BPF}$ at a $D_{L}$ of $25 \mathrm{~cm}$ allowed slightly more $\theta_{v}$ downward movement than PTW (Figures 5 and 6). However, it is better to use PTW mulching at a $D_{L}$ of $15 \mathrm{~cm}$ because of its lower installation cost, despite the slightly lower $\theta_{v}$ values than at a $D_{L}$ of $25 \mathrm{~cm}$ for PTW mulching.
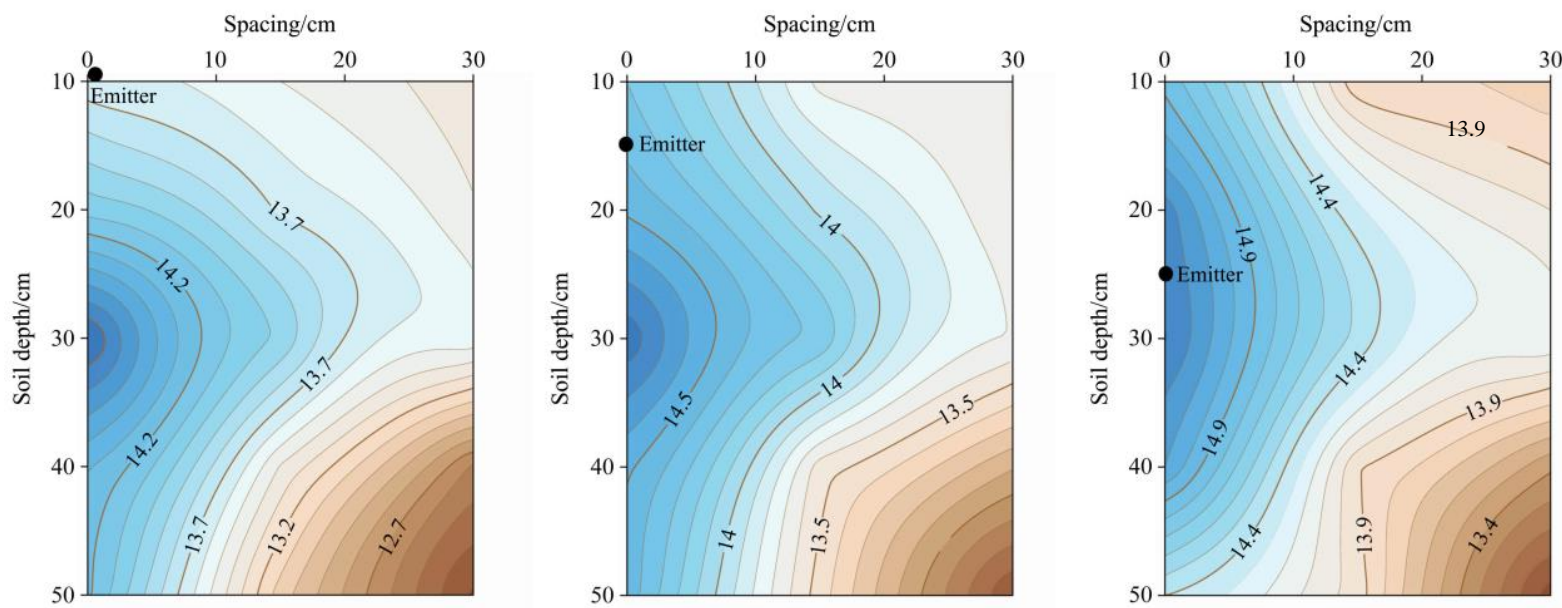

Figure 4 Soil water distribution through the emitter at different drip line depths under no mulching after irrigation for $24 \mathrm{~h}$ 

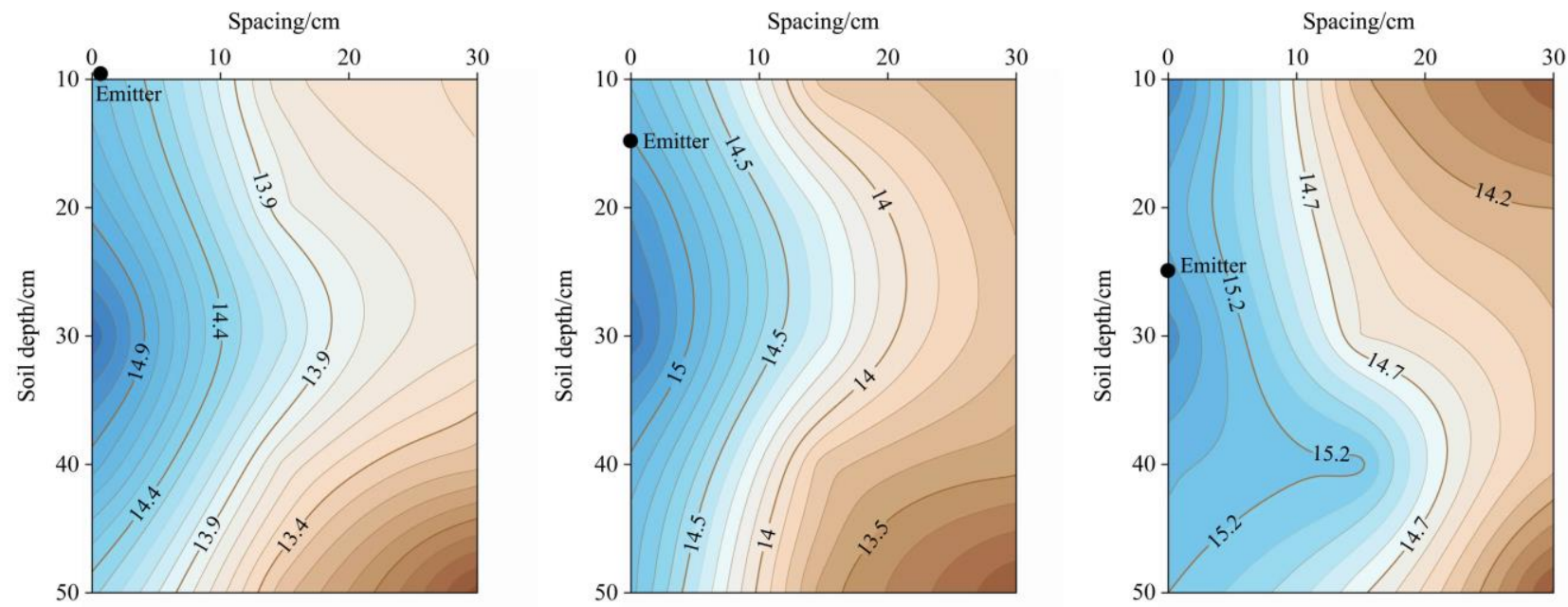

Figure 5 Soil water distribution through the emitter at different drip line depths under black plastic film mulching after irrigation for $24 \mathrm{~h}$
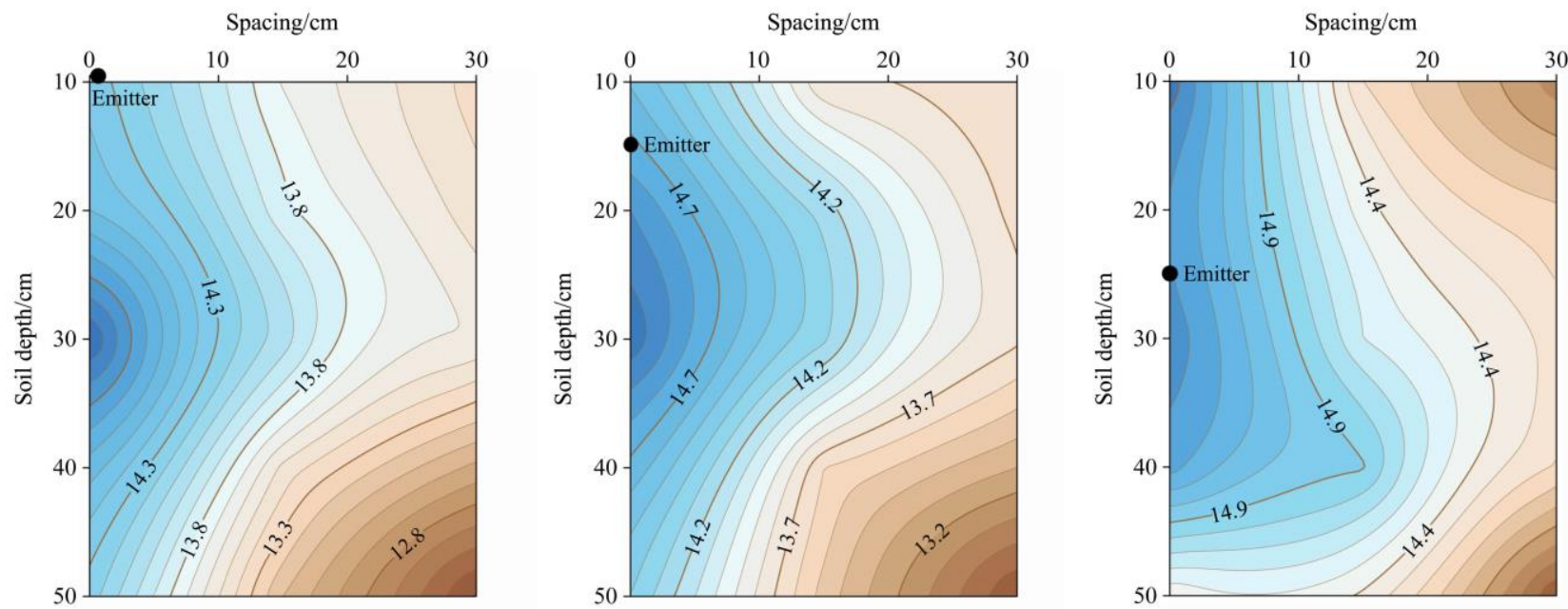

Figure 6 Soil water distribution through the emitter at different drip line depths under palm tree waste mulching after irrigation for $24 \mathrm{~h}$

\subsection{Performance of regression models}

Important factors affecting $\theta_{v}$ values were identified using regression analyses that developed the mathematical models for $\theta_{v}$ as given below:

For MLR

$$
\theta_{v}=14.58+0.071 M T+0.003 D_{L}-0.0089 D-0.047 S
$$

For MNLR

$$
\theta_{v}=15.24 \times M T^{0.004} \times D_{L}^{0.005} \times D^{-0.007} \times S^{-0.026}
$$

Table 6 shows the standard error (SE), $t$-statistic ( $t$-stat), probability ( $p$-value), and variance inflation factor (VIF) for the independent variables (MT, $D_{L}, S$, and $D$ ) in the MLR model at a 95\% confidence interval (CI). The $t$-stat values of the variables should be greater than 1.99 or less than -1.99 to confirm the goodness of fit of the regression coefficients. The $t$-stats of $D_{L}$ and $S$ were greater than 1.99 and less than -1.99 , respectively. The $p$-values for the $D_{L}$ and $S$ were small $(p<0.05)$. The SE of the coefficients of $D_{L}$ and $S$ were 0.004 . Therefore, $D_{L}$ and $S$ were the most significant variables in the calculation of $\theta_{v}$. VIF values of all variables provided in Table 5 were equal to 1 . There were no correlations between variables, which are expressive inputs in the MLR model. For the MNLR analysis at $95 \% \mathrm{CI}, M, D_{L}$, and $S$ were more significant for $\theta_{v}$, where CI did not include zero. The $D$ was not significantly affected because the lower bound and upper bound of CI for $D$ were -0.018 and 0.004 , respectively.

Figure 7 shows the comparisons between the measured $\theta_{v}$ values and $\theta_{v}$ values calculated using the MLR and MNLR models when plotting the regression results of Equations (9) and (10) during the training and testing processes. From the scatter plots, the MLR model provided the least scattered $\theta_{v}$ estimates whereas the MNLR model provided the worst results for the training and testing processes. Table 6 demonstrates the goodness of fit of each regression model during the training and testing processes. The $r$ and $I A$ values of the MLR model were higher and the RMSE value was lower than that of the MNLR model during the training process. The $r$ and IA values for the MLR model were $2.87 \%$ and $9.06 \%$ higher, respectively, and the RMSE value was $6.87 \%$ lower than the values in the MNLR model. Based on the testing dataset, the trends of the MLR and MNLR model results were the same for the training dataset. The MLR model performed better than the MNLR model, with the $r$ and $I A$ values increasing by $3.53 \%$ and $2.64 \%$, respectively, and the RMSE value decreasing by $8.97 \%$.

Table 5 Standard error of regression coefficients, $t$-statistic, probability, and variance inflation factor of independent variables for the multiple linear regression model

\begin{tabular}{cccccc}
\hline & & \multicolumn{5}{c}{ Independent variables } \\
\cline { 3 - 6 } & Intercept & MT & $D_{L}$ & $S$ & $D$ \\
\hline SE & 0.135 & 0.034 & 0.004 & 0.004 & 0.003 \\
$t$-stat & 108.165 & 2.098 & 7.411 & -13.110 & -2.949 \\
$p$-value & $5.43 \times 10^{-85}$ & 0.039 & $1.46 \times 10^{-10}$ & $3.37 \times 10^{-21}$ & 0.004 \\
VIF & & 1.00 & 1.03 & 1.02 & 1.00
\end{tabular}

Note: SE: standard error; $t$-stat: $t$-statistic; $p$-value: probability; VIF: variance inflation factor; MT: mulching types; $D_{L}$ : drip line depth from the soil surface; $S$ : spacing from drip line; $D$ : soil depth. 
Table 6 Statistical performance of the regression models during the training and testing processes

\begin{tabular}{cccccc}
\hline \multirow{2}{*}{$\begin{array}{c}\text { Statistical } \\
\text { parameters }\end{array}$} & \multicolumn{2}{c}{ Training process } & & \multicolumn{2}{c}{ Testing process } \\
\cline { 2 - 3 } \cline { 5 - 6 } & MLR & MNLR & & MLR & MNLR \\
\hline$r$ & 0.861 & 0.837 & & 0.879 & 0.849 \\
$R M S E$ & 0.366 & 0.393 & & 0.345 & 0.379 \\
$I A$ & 0.987 & 0.905 & & 0.934 & 0.910 \\
\hline
\end{tabular}

Note: $r$ : coefficients of correlation; RMSE: root mean square errors; IA: index of agreement.

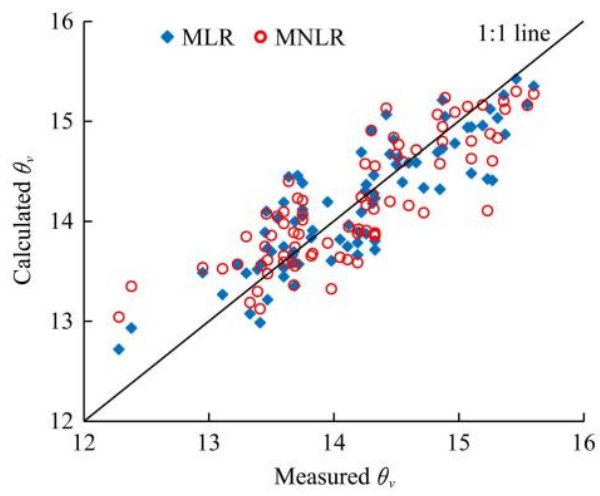

a. Training process

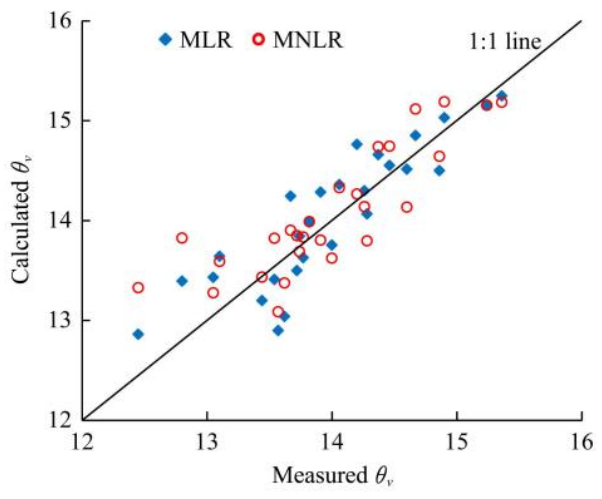

b. Testing process

Figure 7 Scatterplots comparing measured $\theta_{v}$ values and $\theta_{v}$ values calculated by the multiple linear regression (MLR) and multiple

nonlinear regression (MNLR) models

Figure 8 shows the statistical performance values of the MLR and MNLR models during the validation process under different MT. The MLR model provided better agreement between the measured and calculated $\theta_{v}$ values than the MNLR model. This finding is reflected in the high $r(0.87-0.95)$ and $I A(0.89-0.97)$ values, and the low RMSE (0.24-0.44) values for the MLR model. The MLR model for the NM treatment had $9.32 \%$ and $6.84 \%$ higher $r$ and $I A$ values, respectively, than the MNLR model, and it had a $6.04 \%$ lower RMSE value. The $r$ and $I A$ values for the MLR model in the BPF treatment increased by $2.31 \%$ and $2.51 \%$, respectively, whereas the RMSE value decreased by $19.94 \%$. Moreover, $r$ and $I A$ values in the PTW treatment during the validation process increased to $15.08 \%$ and $7.76 \%$, respectively, and the RMSE value decreased to $34.21 \%$ in the MLR model.

There were considerable differences between the calculated $\theta_{v}$ values for the different MT in the MLR and MNLR models, as shown in Figure 8. The MLR model for the prediction of $\theta_{v}$ with the BPF mulching was the most accurate. The MLR model for the BPF treatment yielded the highest $r$ and $I A$ values and the lowest RMSE value compared with the corresponding values for the NM and PTW treatments. For the BPF treatment, modeling with MLR gave $r$ values that were $8.91 \%$ and $1.94 \%$ more accurate than those of the NM and PTW treatments, respectively, and $8.96 \%$ and $1.29 \%$ more accurate, respectively, for the IA values. The MLR model's BPF had RMSE values that were $44.34 \%$ and $19.21 \%$ more accurate for $\theta_{v}$ compared with NM and PTW, respectively. For the PTW treatment, the MLR model produced $r$ and $I A$ values that were $6.84 \%$ and $7.57 \%$ more accurate, respectively, and $31.11 \%$ more accurate for the RMSE values than those obtained for the NM treatment. Hence, the $r, I A$, and RMSE values for the two models confirmed that the MNLR model performed poorly, whereas the MLR model successfully calculated the $\theta_{v}$ values.
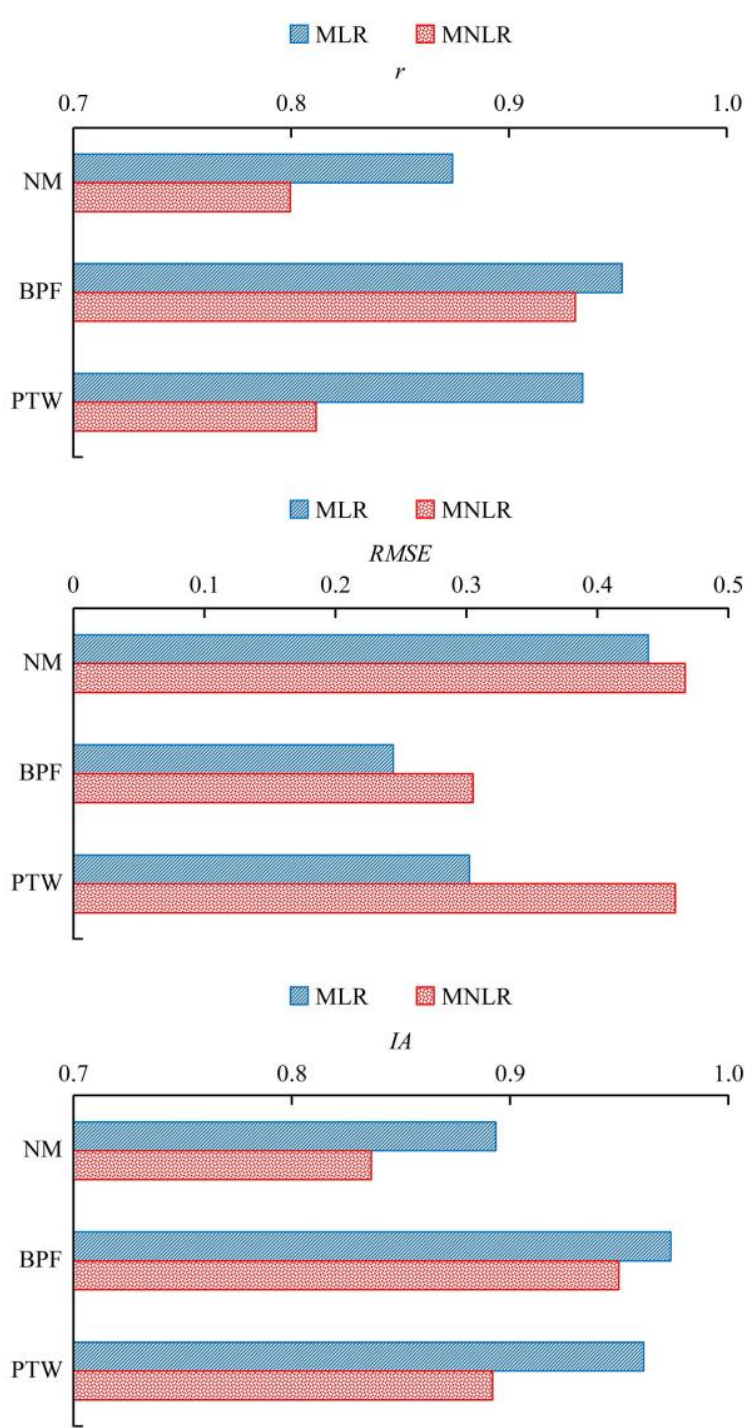

Note: NM: no mulching; BPF: black plastic film; PTW: palm tree waste.

Figure 8 Statistical criteria of coefficients of correlation $(r)$, root mean square error (RMSE), and index of agreement $(I A)$ for the regression models during the validation process

\section{Conclusions}

The effects of different mulching types (MT) in an subsurface drip irrigation (SDI) system on soil water content $\left(\theta_{v}\right)$ distribution were investigated. The use of black plastic film (BPF) or palm tree waste (PTW) enhanced the soil's ability to hold water. In the SDI system, BPF mulching required the application of less water than PTW mulching. Therefore, it is recommended that SDI is beneficial to the soil, and when a drip line depth from the soil surface $\left(D_{L}\right)$ of $15 \mathrm{~cm}$ is installed and mulching is conducted with PTW, there are no additional costs. This approach expands the active soil zone to the roots of crops. Therefore, the strategy 
presented in this study can save water resources in Saudi Arabia's crop fields at a remarkably low cost.

$\theta_{v}$ values were derived as a function of MT, $D_{L}$, spacing from drip line, and soil depth, using multiple linear regression (MLR) and multiple nonlinear regression (MNLR) analyses. The accuracy of the MLR and MNLR models were studied using the coefficients of correlation ( $r$, root mean square errors (RMSE) and index of agreement $(I A)$. Evaluation of the models found that the MLR model fitted well based on the high $r$ and $I A$ values and low RMSE values obtained. The MLR model showed better performance in calculating $\theta_{v}$ values than the MNLR model. The MLR model for the BPF treatment was more accurate than no mulching and PTW treatments. Overall, it is concluded that the MLR model can be used to produce accurate outcomes to predict $\theta_{v}$ values.

\section{Acknowledgements}

The authors extend their appreciation to the Deanship of Scientific Research at King Saud University for funding this work through research group (No. RG-1440-022).

\section{[References]}

[1] Al-Amoud A I. Subsurface drip irrigation for date palm trees to conserve water. ISHS Acta Horticulturae, 2010; 88: 103-114.

[2] Al-Shayaa S, Baig M B, Straquadine G S. Agricultural extension in the Kingdom of Saudi Arabia: difficult present and demanding future. J. Anim. Plant Sci., 2012; 22: 239-246.

[3] Ayars J E, Phene C J, Schoneman R A, Meso B, Dale F, Penland J. Impact of bed location on the operation of subsurface drip irrigation systems. Proc. 5th International Microirrigation Congress, ASABE, 1995; pp.68-174.

[4] Çolak Y B, Yazar A, Gönen E, Eroğlu E Ç. Yield and quality response of surface and subsurface drip-irrigated eggplant and comparison of net returns. Agric. Water Manage., 2018; 206: 165-175.

[5] Zin El-Abedin T K, Mattar M A, Alazba A A. Soil wetting pattern from subsurface drip irrigation as affected by application of a polyacrylamide layer. Irrig. Drain., 2015; 64: 609-618.

[6] Dukes M D, Scholberg J M. Soil moisture controlled subsurface drip irrigation on sandy soils. Appl. Eng. Agric., 2005; 21: 89-101.

[7] Enciso J, Jifon J, Wiedenfeld B. Subsurface drip irrigation of onions: effect of emitter spacing and drip depth on yield. American Society of Agricultural and Biological Engineer, St Joseph, MI, USA, Paper number 052242, 2005.

[8] Soussa H K. Effects of drip irrigation water amount on crop yield, productivity and efficiency of water use in desert regions in Egypt. Nile Basin Water Sci. Eng. J., 2010; 3: 96-109.

[9] Irmak S, Djaman K, Rudnick D R. Effect of full and limited irrigation amount and frequency on subsurface drip - irrigated maize evapotranspiration, yield, water use efficiency and yield response factors. Irrig. Sci., 2016; 34: 271-286.

[10] Bryla D R, Banuelos G S, Mitchell J P. Water requirements of subsurface drip-irrigated fava bean in California. Irrig. Sci., 2003; 22: 31-37.

[11] Magwenzi O. Evaluation of irrigation efficiency in the Swaziland sugar industry. Proc. S. Afr. Sug. Technol. Ass., 2000; 74: 151-154.

[12] Najafi P. Effects of using Subsurface drip irrigation and treated municipal waste water in irrigation of tomato. Pakistan J. Biol. Sci., 2006; 9: 2672-2676.

[13] Zhuge Y P, Zhang X D, Zhang Y L, Liu M D. Tomato root response to subsurface drip irrigation. Pedosphere, 2004; 14: 205-212.

[14] Patel N, Rajput T B S. Effect of subsurface drip irrigation on onion yield. Irrig. Sci. 2009; 2: 97-108.

[15] Al-Harbi A R, Al-Omran A M, El-Adgham F I. Effect of drip irrigation levels and emitters depth on okra (Abelmoschus esculentus) growth. J. Appl. Sci., 2008; 8: 2764-2769.

[16] Douh B, Boujelben A. Water saving and eggplant response to subsurface drip irrigation. Electron. J. Agric. Segm., 2010; 1: 1-12.

[17] Çolak Y B, Yazar A, Sesveren S, Çolak I. Evaluation of yield and leaf water potential (LWP) for eggplant under varying irrigation regimes using surface and subsurface drip systems. Scientia Horticulturae, 2017; 219: $10-21$.

[18] Al-Ghobari H M, Dewida A Z. Integrating deficit irrigation into surface and subsurface drip irrigation as a strategy to save water in arid regions. Agric. Water Manag., 2018; 209: 55-61.

[19] Pisciotta A, Di Lorenzo R, Santalucia G, Barbagallo M G. Response of grapevine (Cabernet Sauvignon cv) to above ground and subsurface drip irrigation under arid conditions. Agric. Water Manage., 2018; 197: 122-131.

[20] Hapeman C, Durham S. Plastic mulch: harmful or helpful? Agric. Res. Mag., 2003; 51: 14-16.

[21] Zhang S, Lövdahl L, Grip H, Tong Y, Yang X, Wang Q. Effects of mulching and catch cropping on soil temperature: soil moisture and wheat yield on the Loess Plateau of China. Soil Tillage Res, 2009; 102: 78-86.

[22] Bu L, Liu J, Zhu L, Luo S, Chen X, Li S, et al. The effects of mulching on maize growth, yield and water use in a semi-arid region. Agric. Water Manag., 2013; 123: 71-78.

[23] Li R, Hou X, Jia Z, Han Q, Ren X, Yang B. Effects on soil temperature, moisture, and maize yield of cultivation with ridge and furrow mulching in the rainfed area of the Loess Plateau, China. Agric. Water Manag., 2013; 116: 101-109.

[24] Li S, Wang Z, Li S, Gao Y, Tian X. Effect of plastic sheet mulch, wheat straw mulch, and maize growth on water loss by evaporation in dryland areas of China. Agric. Water Manag., 2013; 116: 39-49.

[25] Haque M A, Jahiruddin M, Clarke D. Effect of plastic mulch on crop yield and land degradation in south coastal saline soils of Bangladesh. International Soil and Water Conservation Research, 2018; 6(4): 317-324.

[26] Blanco-Canqui H, Lal R. Soil and crop response to harvesting corn residues for biofuel production. Geoderma, 2007; 141: 355-362.

[27] Jordán A, Zavala L M, Gil J. Effects of mulching on soil physical properties and runoff under semi-arid conditions in southern Spain. Catena, 2010; 81: 77-85.

[28] Sharma P, Abrol V, Sharma R. Impact of tillage and mulch management on economics, energy requirement and crop performance in maize-wheat rotation in rainfed subhumid inceptisols, India. Eur. J. Agron., 2011; 34: 46-51.

[29] Jiménez M N, Pinto J R, Ripoll M A, Sánchez-miranda A, Navarro F B Impact of straw and rock-fragment mulches on soil moisture and early growth of holm oaks in a semiarid area. Catena, 2017; 152: 198-206.

[30] Dong H, Li W, Tang W, Zhang D. Early plastic mulching increases stand establishment and lint yield of cotton in saline fields. Field Crop Res., 2009; 111: 269-275.

[31] Wang X, Li Z, Xing Y, Clothier B E, Dierickx W, Oster J, et al. Effects of mulching and nitrogen on soil temperature, water content, nitrate-N content and maize yield in the Loess Plateau of China. Agric. Water Manage., 2015; 161: 53-64.

[32] Liang S M, Cai R, Wang P J, Wang X T, Li Y S, Xu F H, et al Improvements of emergence and tuber yield of potato in a seasonal spring arid region using plastic film mulching only on the ridge. Field Crops Res., 2018; 223: 57-65.

[33] Fan Y, Ding R, Kang S, Hao X, Du T, Tong L, et al. Plastic mulch decreases available energy and evapotranspiration and improves yield and water use efficiency in an irrigated maize cropland. Agric. Water Manage., 2016; 179: 122-131.

[34] Wu Y, Huang F, Jia Z, Ren X, Cai T. Response of soil water, temperature, and maize (Zea may L.) production to different plastic film mulching patterns in semi-arid areas of northwest China. Soil Tillage Res., 2017; 166: $113-121$

[35] Coelho R D, Monteiro R O C, Chaves, S W P, Shirahige F H. Effects of subsurface drip irrigation (SDI) and plastic mulching on melon crop under protected environment. ASABE, 095565. https://doi:10.13031/2013.26915, 2009.

[36] Zotarelli L, Dukes M D, Scholbert J M, Hanselman T, LeFemminella K, Munoz-Carpena R. Nitrogen and water use efficiency of zucchini squash for a plastic mulch system on a sandy soil. Scientia Hort., 2008; 116: 8-16.

[37] Baghani J, Dehghani S H, Sadrghaiini S H. Study the effects of plastic mulches and different irrigation water level on qualitative and quantitative yield of melon in surface and subsurface drip irrigation systems. Iran J. Irrig. Drain., 2010; 4: 175-181.

[38] Wang Y P, Li X G, Zhu J, Fan C Y, Kong X J, Turner N C, et al. Multi-site assessment of the effects of plastic-film mulch on dryland maize productivity in semiarid areas in China. Agric. For. Meteorol., 2016; 220: 160-169. 
[39] Ma D, Chen L, Qu H, Wang Y, Misselbrook T, Jiang R. Impacts of plastic film mulching on crop yields, soil water, nitrate, and organic carbon in Northwestern China: A meta-analysis. Agric. Water Manag., 2018; 202: 166-173.

[40] Legates D R, McCabe Jr G J. Evaluating the use of goodness-of fit measures in hydrologic and hydroclimatic model validation. Water Resour. Res., 1999; 35: 233-241.

[41] Licciardello F, Zema D A, Zimbone S M, Bingner R L. Runoff and soil erosion evaluation by the AnnAGNPS model in a small Mediterranean watershed. Trans. ASABE, 2007; 50: 1585-1593.

[42] Willmot C J. On the validation of models. Phys. Geogr., 1981; 2: 184-194.

[43] Al-Ghobari H M, El-Marazky M A. Surface and subsurface irrigation systems wetting patterns as affected by irrigation scheduling techniques in an arid region. Afr. J. Agric. Res. 2012; 7: 5962-5976.

[44] Gan Y, Siddique Kadambot H M, Turner N C, Li, X G, Niu J Y, Yang C, et al. Ridge-furrow mulching systems-an innovative technique for boosting crop productivity in semiarid rain-fed environments. Adv. Agron. 2013; 118: 429-476.

[45] Dong Q, Yang Y, Yu K, Feng H. Effects of straw mulching and plastic film mulching on improving soil organic carbon and nitrogen fractions, crop yield and water use efficiency in the Loess Plateau, China. Agric. Water Manag., 2018; 201: 133-143.

[46] Liu T, Wang B, Xiao H, Wang R, Yang B, Cao Q, et al. Differentially improved soil microenvironment and seedling growth of Amorpha fruticosa by plastic, sand and straw mulching in a saline wasteland in northwest China. Ecol Eng., 2018; 122: 126-134.

[47] Mokh F, Nagaz K, Masmoudi M M, Mechlia N B. Effects of surface and subsurface drip irrigation regimes with saline water on yield and water use efficiency of potato in arid conditions of Tunisia. J. Agric. Environ. Inter. Dev., 2014; 108: 227-246.

[48] Solomon K. Subsurface drip irrigation: product selection and performance. In: Jorsengen G S, Norum K N (Eds.), Subsurface drip irrigation: theory, practices and applications. CATI Publication, No. 9211001, 1993.

[49] Assouline S. The effects of microdrip and conventional drip irrigation on water distribution and uptake. Soil Sci. Soc. Am. J., 2002; 66: 1630-1636.

[50] Grabow G L, Huffman R L, Evans R, Jordan D, Nuti R C. Water distribution from a subsurface drip irrigation system and drip line spacing effect on cotton yield and water use efficiency in a coastal plain soil. Trans. ASABE, 2006; 49: 1823-1835.

[51] Badr M A. Spatial distribution of water and nutrients in root zone under surface and subsurface drip irrigation and cantaloupe yield. World J.
Agric. Sci., 2007; 3: 747-756.

[52] Shirahatti M S, Itnal C J, Mallikarjunappa Gouda D S. Impact of differential methods of irrigation on yield levels of cotton in red soils. Karnataka J. Agric. Sci., 2007; 20: 96-98.

[53] Nasrabad G G, Rajput T B S, Patel N. Soil water distribution and simulation under subsurface drip irrigation in cotton (Gossypium hirsutum) Indian J. Agric. Sci., 2013; 83: 63-70.

[54] Arbat G P, Lamm F R, Abou Kheira A A. Subsurface drip irrigation emitter spacing effects on soil water redistribution, corn yield, and water productivity. Appl. Eng. Agric., 2010; 26: 391-399.

[55] Bajracharya R M, Sharma S. Influence of drip-irrigation method on performance and yields of cucumber and tomato. Int. J. Appl. Sci. Eng. Tech., 2005; 1: 1-7.

[56] Douh B, Boujelben A, Khila S, Bel Haj Mguidiche A. Effect of subsurface drip irrigation system depth on soil water content distribution at different depths and different tines after irrigation. Larhyss J., 2013; 13 : $7-16$.

[57] Wang Y, Xie Z, Malhi S S, Vera C L, Zhang Y, Wang J. Effects of rainfall harvesting and mulching technologies on water use efficiency and crop yield in the semi-arid loess plateau, China. Agric. Water Manag., 2009; 96(3): 374-382.

[58] Liu J, Bu L, Zhu L. Optimizing plant density and plastic film mulch to increase maize productivity and water-Use efficiency in semiarid areas. Agron. J., 2014; 106(4): 1138-1146.

[59] Badr A E, Abuarab M E. Soil moisture distribution patterns under surface and subsurface drip irrigation systems in sandy soil using neutron scattering technique. Irrig. Sci., 2011; 31: 317-332.

[60] Rodríguez-Sinobas L, María G, Raúl S, Javier B. Evaluation of drip and subsurface drip irrigation in a uniform loamy soil. Soil Sci., 2012; 177: $147-152$.

[61] Zhao H, Wang R Y, Ma B L, Xiong Y C, Qiang S C, Wang C L, et al Ridge-furrow with full plastic film mulching improves water use efficiency and tuber yields of potato in a semiarid rainfed ecosystem. Field Crops Research, 2014; 161: 137-148.

[62] Li S, Li Y, Lin H, Feng H, Dyck M. Effects of different mulching technologies on evapotranspiration and summer maize growth. Agric. Water Manag. 2018; 201: 309-318.

[63] Ashrafuzzaman M, Abdul-Halim M, Ismail M R, Shahidullah S M, Hossain M A. Effect of plastic mulch on growth and yield of chilli (Capsicum annuum L.). Braz. Arch. Biol. Technol., 2011; 54: 321-330.

[64] Thorburn P J, Cook F J, Bristow K L. Soil-dependent wetting from trickle emitters: implications for system design and management. Irrig. Sci., 2003; 22: 121-127. 